\section{El paratexto del traductor: antiguos y nuevos debates}

\section{Nathaly Bernal}

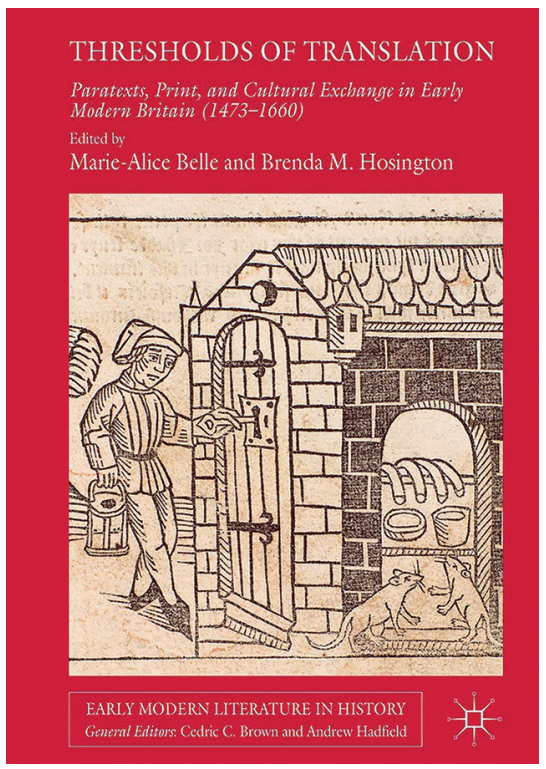

Marie-Alice Belle y Brenda M. Hosington (eds.), Thresholds of Translation: Paratexts, Print, and Cultural Exchange in Early Modern Britain (1473-1660), ISBN: 9783319727721, Suiza, Springer, 2018, $327 \mathrm{pp}$.

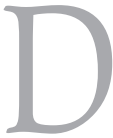
ado que el principal objeto de estudio de este libro son los paratextos, vale la pena considerar aquellos empleados por las propias autoras. Lo primero que llama la atención al analizar Thresholds of Translation son las similitudes de este texto con Renaissance Paratexts, publicado por Helen Smith y Louise Wilson en 2011. Estas semejanzas se advierten en dos direcciones: en un primer nivel material, al comparar aspectos como la inclusión y la organización de los paratextos (índice, lista de figuras, información sobre los autores de los capítulos, agradecimientos.); y en un nivel más profundo, al contrastar los temas y periodos estudiados. En la introducción, Belle y Hosington retoman conceptos propuestos por Gerard Genette en Umbrales (2001); y por Smith y Wilson, como cuando éstas afirman que los paratextos "work both outwards, altering the contexts and possibilities of the book's reception, and inwards, transforming not only the appearence but the priorities and tone of the text" (2011: 6), pero sólo parten de allí para hacer el análisis que les concierne y que consistirá en su aporte: una reflexión en términos traductológicos.

Antes de dar entrada al contenido del libro, permítaseme una consideración sobre la forma en que Belle y Hosington abordan el tema del prólogo del traductor, para lo cual citan uno escrito por Joseph Rutter en 1637. Allí, las autoras emplean expresiones como "cleverly" o "he also displays a striking awareness of what Gerard Genette would call the 'vestibular' nature of the genre" (1), ${ }^{1}$ que evidencian la sorpresa que sienten ante el proceder de Rutter. De esto se puede interpretar que las autoras consideran que el traductor no tendría por qué conocer las funciones de 'umbral' de un prefacio, antes de que Genette lo pusiera en esos términos a finales del siglo XX. Esta explicación pudo haberse dado quizá en otros términos: es Genette quien observa los patrones y las particularidades de los paratextos usados por numerosos autores a lo largo de la historia, y es sólo con base en esta indagación que formula etiquetas para referirse a procesos, por lo demás, y como queda claro después de la lectura de este libro, nada novedosos.

Con respecto a las funciones de los paratextos durante el Renacimiento, Belle y Hosington identifican aquellas de

1 Todas las citas pertenecientes a Thresholds of Translation: Paratexts, Print, and Cultural Exchange in Early Modern Britain (1473-1660) corresponden a Belle y Hosington, 2018, por lo cual sólo se anota el número de página. 
defensa y recomendación de un determinado autor u obra, con el fin de obtener reconocimiento social y cultural, y aún más importante, señalan que por medio de estos recursos, "writers and printers attempted, with variable success, to shape the reception of the printed text" (3).

En este sentido, Belle y Hosington reafirman la idea de Genette de que el paratexto está siempre al servicio, más o menos comprendido y cumplido, de una lectura más pertinente a los ojos del autor y sus aliados (8). Genette sugiere que esta es la razón de ser de los paratextos - al menos en la época actual—, pero las autoras parecen desestimar otros aspectos de corte histórico, propuestos ya por Smith y Wilson: durante el Renacimiento, los lectores estaban más involucrados con los textos y creaban sus propios paratextos, ya no en función de dichos actores, sino como una manera de enriquecer su propia experiencia de lectura, "choosing a particular binding, ordering the contents, and, perhaps most importantly, writing in their pages" (9).

El cuerpo de la obra está dividido en dos partes. La primera, aborda en cuatro capítulos (2-5) la configuración de la traducción por medio del traslado textual, material y cultural, en libros publicados en los primeros años de la Edad Moderna; y la segunda, presenta seis casos de estudio (capítulos 6-11). La primera parte empieza con "Matter in the Margins", de la propia Helen Smith. Como el título sugiere, este capítulo trata la forma en que los traductores utilizaban todos los espacios en la página - y especialmente los márgenes-, como "a zone of thought and intelectual negotiation" (28), y la relación entre las palabras y su carga de significado. En el tercer capítulo, "The Translator's Visibility in Early Printed PortraitImages and the Ambiguous Example of Margaret More Roper", A. E. B. Coldiron parte de la crítica que hace Venuti a la invisibilidad del traductor, para analizar qué tan manifiestos estaban estos actores en los manuscritos medievales, a partir de la inclusión de sus propios retratos en la obra.

A continuación, Hosington discute en "Textual Standard-Bearers: Translated Titles and Early Modern English Print" las relaciones entre texto y título, en quién recaía la elección de este último y su función publicitaria. En el último capítulo de esta sección, "Spain in Translation: Peritextual Representations of Cultural Difference, 1614-1625", Joyce Boro explora las relaciones textuales y políticas entre Inglaterra y España en una década que fue fértil para el intercambio cultural entre ambas regiones.

La segunda parte del libro examina los paratextos en seis casos concretos de traducción. Belle abre la sección con "Knights, 
Schoolmasters, and 'Lusty Ladies White': Addressing Readers in the Paratexts of Gavin Douglas's Fourth Book of Eneados (15131553)", donde analiza el rol de los paratextos "as an arena of interpretive debate and negotiation" (140), los cuales moldearon en gran parte la recepción de Virgilio en este contexto. Alessandra Petrina retoma en "Approaching Petrarch's Trionfi: Paratexts in the Early Modern Scottish Translations" las nociones de paratexto expuestas por Genette, para analizar aquellos presentes en dos traducciones escocesas de Petrarca, una de William Fowler y otra de Anna Hume.

En el octavo capítulo, Gabriela Schmidt estudia la variedad de paratextos en la traducción que hace Ralph Robinson de Utopía, libro ya de por sí variado, en relación con la diversidad de lectores y de mercados en los que tuvo acogida durante los primeros años de sus ediciones y reediciones. A continuación, Giovanni Iamartino y Alessandra Manzi estudian los paratextos que escribe Henry Carey para las traducciones al inglés de Romulo e Il Tarquinio Superbo, de Virgilio Malvezzi, a la luz de las posturas políticas presentes en la obra de este último y la agenda política del propio traductor, "example of the role of translation as a more or less explicit political activity during one of the most turbulent periods in British history" (209).

En "The Paratexts to Ben Jonson's Translation of Horace's Ars poetica (1640): A Contemporary Reading of Jonson's Poetics", Line Cottegnies toma los paratextos que introduce Ben Jonson para la traducción de Ars poetica, de Horacio, como fuente de investigación sobre su propia poética. Cottegnies estudia hasta qué punto esta relación de Jonson con la obra de Horacio ayudó a conformar su manifiesto poético, lo cual también tendría implicaciones en su faceta como traductor. Por último, Warren Boutcher analiza los vínculos entre traducción y comercialización en las décadas de 1640 a 1660, y para esto estudia los casos de Humphrey Moseley y William London, por cuanto estos promovieron intercambios culturales importantes por medio del comercio - y por supuesto, la traducción y la lectura - de libros en inglés, por entonces considerada lengua vernácula.

Si bien todos los autores estudian fenómenos similares, la obra presenta variedad de casos, idiomas y tipos de texto fuente. Los capítulos pueden ser de interés general, si se quiere conocer los procesos de traducción durante el Renacimiento; pero también particular, si se estudia la obra de alguno de los autores, traductores o editores incluidos. Más que un compendio teórico sobre el paratexto, como sucede con la obra de Genette, Belle y Hosington recopilan en su libro casos, algunos de los cuales arrojan mucha luz sobre 
la relación del traductor con el texto fuente, lo que permite reflexionar sobre la posible evolución de dicha relación hasta el presente.

Finalmente, en este libro es evidente la intención de legitimar la práctica del traductor, y, sobre todo, de recordarle al lector que, históricamente, este actor ha tenido un lugar privilegiado en lo que a la producción de paratextos se refiere. La obra, sin duda, redescubre esta faceta, dado que en los ámbitos académico, cultural y editorial no se ha generado el suficiente espacio de debate sobre el tema, y son pocas las investigaciones de paratextos en los siglos comprendidos entre la época investigada por Belle y Hosington y el siglo XX, que es cuando Genette publica su estudio y acuña el término que ahora nos es familiar: el paratexto.

\section{REFERENCIAS}

Belle, Marie-Alice y Brenda M. Hosington (eds.) (2018), Thresholds of Translation: Paratexts, Print, and Cultural Exchange in Early Modern Britain (1473-1660), Suiza, Springer.

Genette, Gerard (2001), Umbrales, México, Siglo XXI.

Smith, Helen y Wilson, Louise (Eds.) (2011), Renaissance Paratexts, Cambridge, Cambridge University Press.

NathaLY Bernal. Licenciada en Inglés por la Universidad Industrial de Santander (UIS), Colombia, y becaria de la Maestría en Traducción de El Colegio de México (Colmex), México. Traduce del inglés y del francés. Dentro de sus intereses se cuentan la traducción literaria y la crítica de traducciones. En la actualidad, realiza su tesis sobre la traducción de ensayo a partir de la obra de Virginia Woolf, y prepara un libro con la traducción de dos ensayos epistolares de la misma autora. 